\title{
CONSTRAINING LIDAR STAND-ALONE RETRIEVALS WITH LUNAR PHOTOMETRY MEASUREMENTS
}

\author{
Pablo Ortiz-Amezcua ${ }^{1,2 *}$, Juan Luis Guerrero-Rascado ${ }^{1,2}$, Jose Antonio Benavent-Oltra ${ }^{1,2}$, Roberto \\ Román $^{1,2}$, Christine Böckmann ${ }^{3}$, Lucas Alados-Arboledas ${ }^{1,2}$ \\ ${ }^{1}$ Andalusian Institute for Earth System Research (IISTA-CEAMA), Granada, \\ Spain,*portizamezcua@ugr.es \\ ${ }^{2}$ Department of Applied Physics, University of Granada, Spain \\ ${ }^{3}$ Institute for Mathematics, University of Potsdam, Germany
}

\begin{abstract}
This study combines atmospheric optical information measured with lidar and nocturnal photometers in order to find configurations that allow for the retrieval of particle microphysical properties without " $3+2$ " lidar setups. It has been carried out using data measured at the EARLINET Granada station during the experimental campaign SLOPE in the framework of ACTRIS-2 project.
\end{abstract}

\section{INTRODUCTION}

In the last decades, lidar technique has become a key methodology to obtain vertical profiles of atmospheric aerosol properties at several wavelengths with high spatial and temporal resolution. Multiwavelength Raman lidar measurements allow for stand-alone microphysical retrievals, i. e., the calculation of particle microphysical properties using only Raman lidar data, but the minimum requirement is having a setup with 3 profiles of backscatter coefficient $(355,532,1064 \mathrm{~nm})$ and 2 of extinction coefficient $(355,532 \mathrm{~nm})$, the so-called " $3+2$ " configuration $[1,2]$. However, there are a lot of lidar systems, in particular inside EARLINET [3] and LALINET [4] networks, that do not fulfill this requirement.

The aim of this work is to find alternative setups that, in combination with lunar photometry measurements, can provide reasonably good inputs for microphysical retrievals

\section{LOCATION, INSTRUMENTATION AND METHODOLOGY}

The measurements have been performed at Granada $\left(37.16^{\circ} \mathrm{N}, 3.61^{\circ} \mathrm{W}, 680 \mathrm{~m}\right.$ asl), a medium-size city in Southeastern Spain affected by air masses mainly coming from the Atlantic
Ocean, Europe, North Africa and the Mediterranean Basin. The data for this study were obtained in the context of SLOPE, a field campaign carried out in summer 2016 to gather data useful for testing the retrieval schemes through inversion of remote sensing observations.

\subsection{Multiwavelength Raman lidar and microphysical algorithm}

The vertical profiles of particle optical properties were obtained using signals from the multiwavelength Raman lidar system MULHACEN (LR331D400, Raymetrics Inc.), configured in a monostatic biaxial alignment pointing vertically to the zenith. A pulsed $\mathrm{Nd}$ :YAG laser with emission at wavelengths of 355,532 and $1064 \mathrm{~nm}$ is used as a radiation source, and the backscattered signal is collected by a Cassegranian telescope and splitted to detect elastic signals at 355, 532 (in parallel and perpendicular polarizations) and $1064 \mathrm{~nm}$ and Raman shifted signals at 387, 607 and $408 \mathrm{~nm}$.

Night-time lidar signals are used to obtain particle backscatter $(\beta)$ and extinction $(\alpha)$ coefficients using the Raman algorithm [5]. The resulting set of $3 \beta$ (at 355, 532 and $1064 \mathrm{~nm}$ ) and $2 \alpha$ (at 355 and $532 \mathrm{~nm}$ ) is employed as input to obtain particle microphysical properties with a regularization method. The used algorithm (UP) was developed at the University of Potsdam [2] in the framework of EARLINET [6], and is based on explicitly solving the equations that relate the particle microphysical and optical properties by means of Truncated Singular Value Decomposition (TSVD) regularization. The resulting particle properties, namely volume concentration $\left(v_{c}\right)$, effective radius $\left(r_{e f f}\right)$, single scattering albedo (SSA) and real and imaginary parts of refractive index (RRI, IRI), constitute the reference values in the present work. 


\subsection{Sun/sky/lunar photometer}

The nocturnal aerosol optical depth (AOD) is measured with the sun-sky-lunar CE318-T photometer (Cimel Electronique) [7], developed to extend the performance of the common sunphotometers in AERONET (Aerosol Robotic Network) [8] to both daytime and night-time measurements.

This instrument performs the daytime AERONET routine measurements, but also night-time direct measurements of the lunar irradiance at nominal wavelengths of $1640,1020,870,670,500$ and 440 $\mathrm{nm}$. A sequence of three measurements of the radiation reflected by the Moon is taken every 30 $\mathrm{s}$ at each wavelength. AOD is obtained from these irradiances following the method of [7], which uses the ROLO model [9] to calculate the lunar extraterrestrial irradiance. The nocturnal measurements can be taken during 50\% of the Moon cycle, extending the diurnal measurements during this period.

\subsection{Simulation of missing lidar channels with spectral AOD}

In order to test the accuracy of the microphysical retrievals for the combination of "incomplete" lidar systems with lunar photometer, several possible configurations were simulated and compared with the reference $3+2$ results. To this end, the missing lidar information was reconstructed using columnar Angström Exponent $(A E)$ of spectral AOD's from photometer measurements, and following Angström equation for wavelengths $\lambda_{1}$ and $\lambda_{2}$ :

$$
X\left(\lambda_{2}\right)=X\left(\lambda_{1}\right) \cdot\left[\frac{\lambda_{2}}{\lambda_{1}}\right]^{-A E_{\lambda_{1}, \lambda_{2}}}
$$

where $X$ stands for $\alpha$ or $\beta$.

With this in mind, the following lidar configurations were chosen and completed with lunar photometer measurements:

- 3+1 (355): three $\beta$ at 355, 532, $1064 \mathrm{~nm}$ and one $\alpha$ at $355 \mathrm{~nm}$ are used. Missing $\alpha_{532}$ profile is generated from $\alpha_{355}$ profile and $A E_{440,670}$ from photometer using Eq. (1).
- 3+1 (532): three $\beta$ at 355, 532, $1064 \mathrm{~nm}$ and one $\alpha$ at $532 \mathrm{~nm}$ are used. Missing $\alpha_{355}$ profile is generated from $\alpha_{532}$ profile and $A E_{440,670}$ from photometer.

- 2+2: two $\beta$ and two $\alpha$ at 355 and $532 \mathrm{~nm}$ are used. Missing $\beta_{1064}$ profile is generated combining $\beta_{532}$ profile and $A E_{670,1640}$ in Eq. (1).

\section{RESULTS}

Two night-time cases measured during SLOPE field campaign at Granada were selected to test the proposed methodology.

\subsection{Case A}

It corresponds to a measurement on 18th May 2016 at 22:00-22:30 UTC. According to satellite information and transport models (not shown here), the event is classified as biomass burning particles from North American forest fires.

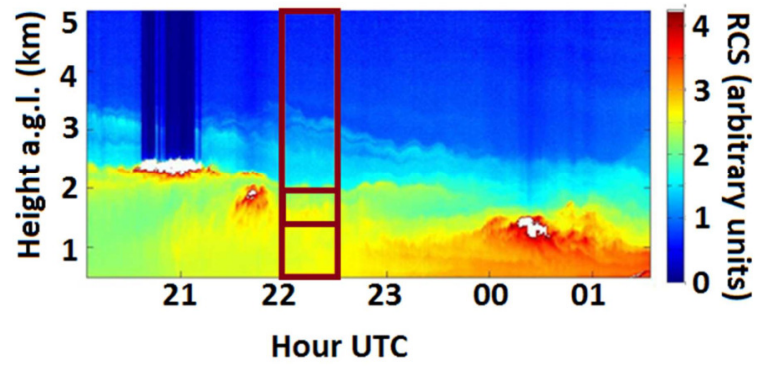

Figure 1: Time evolution of the lidar range corrected signal (RCS) at $532 \mathrm{~nm}$ for case A. Brown boxes indicate the period and region selected for microphysical analysis

The time evolution of the lidar range corrected signal (RCS) at $532 \mathrm{~nm}$ (Fig. 1) shows a multilayered aerosol structure up to $3.5 \mathrm{~km}$ above ground level (agl). A region from 1.4 to $2 \mathrm{~km}$ agl (brown box) was selected to perform the microphysical analysis.

Simultaneous lunar photometer measurements indicated $\mathrm{AOD}_{440}$ of 0.28 . The spectral AOD was used to simulate the different configurations for microphysical retrievals, and the results (Fig. 2) showed similar values to the reference set $(3+2)$ retrievals, since most of the differences among configurations were inside the uncertainty bars (which indicate a statistical standard deviation of the retrieval). 

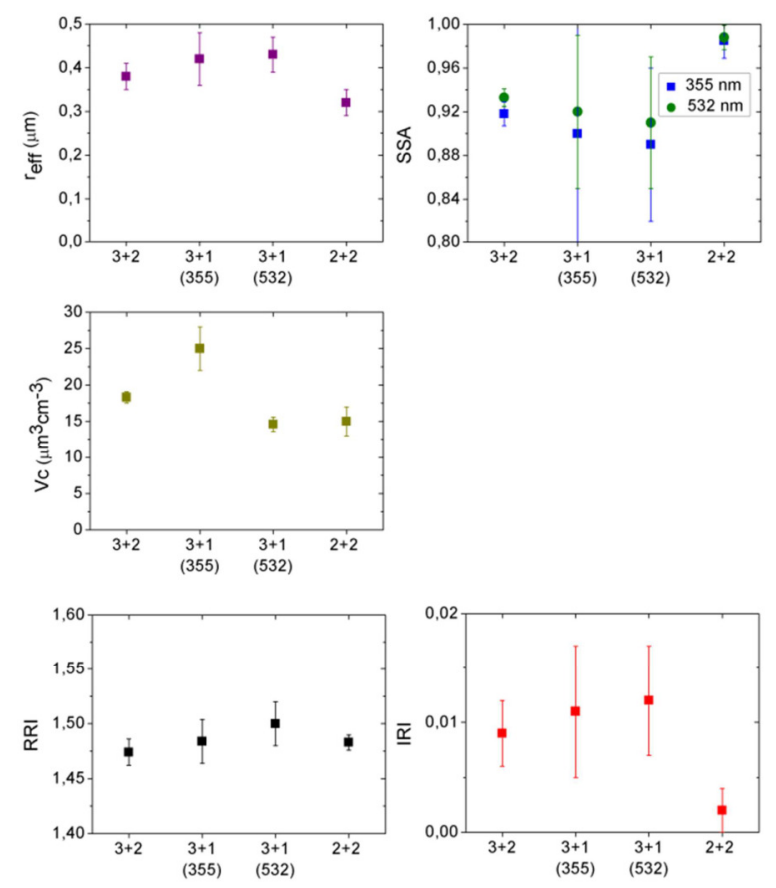

Figure 2: Effective radius ( $r_{\text {eff }}$ ), single scattering albedo (SSA), volume concentration $\left(V_{c}\right)$, real and imaginary parts of refractive index (RRI, IRI) retrieved for Case A using the complete lidar setup $(3+2)$ and different combinations with lunar photometer

\subsection{Case B}

The second case from SLOPE, with different aerosol type, corresponds to an event of local pollution at Granada on 17th June 2016 at 20:3021:00 UTC.

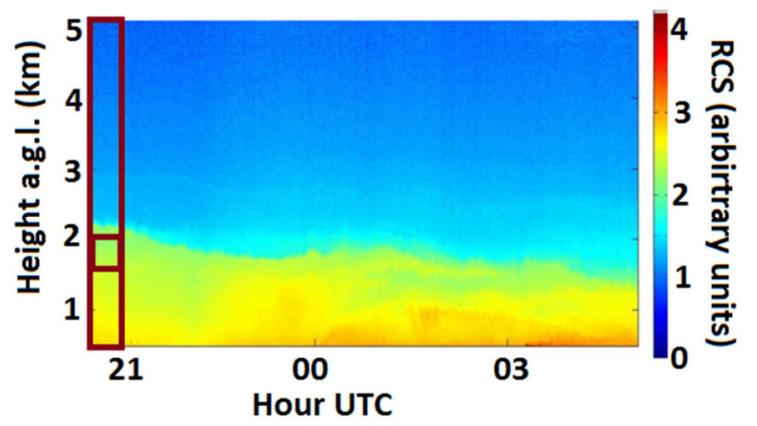

Figure 3: Time evolution of the lidar RCS at $532 \mathrm{~nm}$ for case B. Brown boxes indicate the period and region selected for microphysical analysis

The particle microphysical properties were calculated for an aerosol layer between 1.5 and 2 $\mathrm{km}$ agl (brown box in Fig. 3, corresponding to time evolution of RCS at $532 \mathrm{~nm}$ ).
For this case, the microphysical retrievals resulting from the different combinations made with lunar photometer spectral AOD (Fig. 4) also agreed well with the $3+2$ setup. However, the deviations are slightly higher than those for case A, what can be attributed to a lower AOD, taking the value of 0.10 at $440 \mathrm{~nm}$.
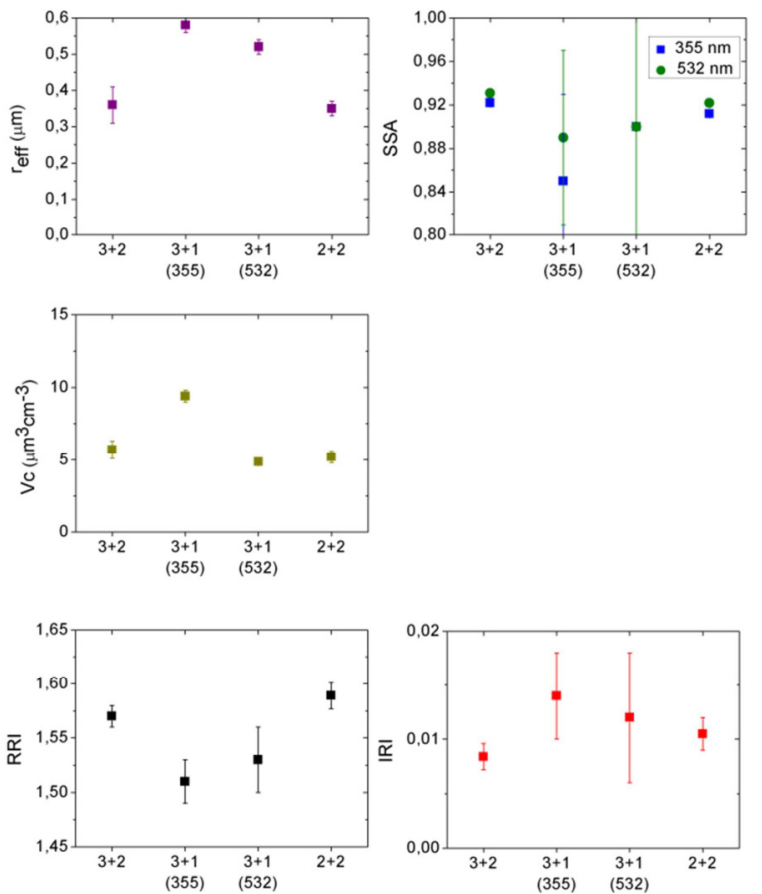

Figure 4: Microphysical properties (same as Fig. 2) for Case B with different lidar + lunar photometer setups.

The deviation to the $3+2$ retrieval of all simulated configurations was averaged for each microphysical property and for cases $\mathrm{A}$ and $\mathrm{B}$ (Table 1). It can be observed that the parameter with most sensitivity to the changes for the studied cases is IRI, and that SSA and RRI are almost unaffected by the variations.

Table 1: Deviations from the 3+2 configuration retrieval, averaged for all photometer configurations in cases $A$ and $B$

\begin{tabular}{|l|l|l|}
\hline Microphysical & \multicolumn{2}{|l|}{ Mean Deviation (\%) } \\
\cline { 2 - 3 } Properties & Case A & Case B \\
\hline $\mathbf{r}_{\text {eff }}$ & 13 & 36 \\
\hline SSA & 4 & 4 \\
\hline Vc & 25 & 30 \\
\hline RRI & 1 & 3 \\
\hline IRI & 44 & 45 \\
\hline
\end{tabular}




\section{CONCLUSIONS AND OUTLOOK}

This work explores the combination of an "incomplete" lidar system (without $3+2$ setup) with the night-time AOD from lunar photometer, finding that it can be used to derive alternative input setups for a lidar stand-alone regularization algorithm to obtain particle microphysical properties. Optimistic results have been found for two test cases: there are small differences among different datasets (sometimes they are inside the standard deviation bars). Comparing the two cases, slightly better results are obtained for a biomass burning case, which presented higher AOD.

In future work, more cases and more configurations will be analyzed in order to extract a general behavior about the best configurations and the relationship with the AOD.

\section{ACKNOWLEDGEMENTS}

This work was supported by the Andalusia Regional Government through project P12-RNM2409, by the Spanish Ministry of Economy and Competitiveness through projects CGL201345410-R and CGL2016-81092-R and by the European Union's Horizon 2020 research and innovation programme through project ACTRIS-2 (grant agreement No 654109). The authors thankfully acknowledge the FEDER program for the instrumentation used in this work.. This work was also partially funded by the University of Granada through "Plan Propio. Programa 9. Convocatoria 2013".

\section{References}

[1] Müller, D., Wandinger, U., Ansmann, A., 1999: Microphysical particle parameters from extinction and backscatter lidar data by inversion with regularization: Theory, Appl. Optics 38, 2346-2357.

[2] Böckmann, C., 2001: Hybrid regularization method for the ill-posed inversion of multiwavelenght lidar data to determine aerosol size distributions, Appl. Optics 40, 1329-1342.

[3] Pappalardo, G., Amodeo, A., Apituley, A., Comeron, A., Freudenthaler, V., Linné, H., Ansmann, A., Bösenberg, J., D'Amico, G., Mattis, I., Mona, L., Wandinger, U., Amiridis,
V., AladosArboledas, L., Nicolae, D., Wiegner, M., 2014: EARLINET: towards an advanced sustainable European aerosol lidar network, Atmos. Meas. Tech. 7, 2389-2409.

[4] Guerrero-Rascado, J. L., Landulfo, E., Antuña, J. C., Barbosa, H. M. J., Barja, B., Bastidas, A. E., Bedoya, A. E., da Costa, R., Estevan, R., Forno, R. N., Gouveia, D. A., Jimenez, C., Larroza, E. G., Lopes, F. J. S., MontillaRosero, E., Moreira, G. A., Nakaema, W. M., Nisperuza, D., Alegria, D., Manera, M., Otero, L., Papandera, S., Pallota, J. V., Pawelko, E., Quel, E. J., Ristori, P., Rodrigues, P. F., Salvador, J., Sanchez, M., Silva, A., 2016: Latin American Lidar Network (LALINET): diagnosis on network instrumentation, $J$. Atmos. Sol. Terr. Phys. 138-139, 112-120.

[5] Ansmann, A., Wandinger, U., Riebesell, M., Weitkamp, C., Michaelis, W., 1992: Independent measurement of extinction and backscatter profiles in cirrus clouds by using a combined Raman elastic-backscatter lidar, Appl. Opt. 31, 7113-7131.

[6] Müller, D., Böckmann, C., Kolgotin, A., Schneidenbach, L., Chemyakin, E. V., Rosemann, J., Znak, P., Romanov, A., 2016: Microphysical particle properties derived from inversion algorithms developed in the framework of EARLINET, Atmos. Meas. Tech. 9, 5007-5035.

[7] Barreto, A., Cuevas, E., Granados-Muñoz, M. J., Alados-Arboledas, L., Romero, P. M., Gröbner, J., Kouremeti, N., Almansa, A. F., Stone, T., Toledano, C., Román, R., Sorokin, M., Holben, B., Canini, M., Yela, M., 2016: The new sun-sky-lunar Cimel CE318-T multiband photometer - a comprehensive performance evaluation, Atmos. Meas. Tech. 9, 631-654.

[8] Holben, B., N., Eck, T. F., Slutsker, I., Tanré, D., Buis, J. P., Setzer, A., Vermote, E., Reagan, J. A., Kaufman, Y. J., Nakajima, T., Lavenu, F., Jakowiak, I., Smirnov, A., 1998: AERONET - A Federated Instrument Network and Data Archive for Aerosol Characterization, Remote Sens. Environ. 66(1), 1-16.

[9] Kieffer, H. H., Stone, T. C., 2005: The spectral irradiance of the moon, Astron. J. 129, 28872901. 